\title{
Interneuron Desynchronization Precedes Seizures in a Mouse Model of Dravet Syndrome
}

\author{
Conny H. Tran, ${ }^{1}$ Michael Vaiana, ${ }^{2,3 *}$ Johan Nakuci, ${ }^{4 *}$ Ala Somarowthu, ${ }^{5}$ Kevin M. Goff, ${ }^{6}{ }^{\circ}$ Nitsan Goldstein, ${ }^{6}$ \\ Priya Murthy, ${ }^{7}$ Sarah F. Muldoon, ${ }^{2,3,4}$ and ${ }^{-E t h a n ~ M . ~ G o l d b e r g, ~}{ }^{5,8,9}$ \\ ${ }^{1}$ Drexel College of Medicine, Philadelphia, Pennsylvania 19129, ${ }^{2}$ Department of Mathematics, ${ }^{3}$ CDSE Program, ${ }^{4}$ Neuroscience Program, University at \\ Buffalo, State University of New York, Buffalo, New York 14260, ${ }^{5}$ Department of Pediatrics, Division of Neurology, The Children's Hospital of Philadelphia, \\ Philadelphia, Pennsylvania 19104, ${ }^{6}$ Neuroscience Graduate Group, Perelman School of Medicine at The University of Pennsylvania, Philadelphia, \\ Pennsylvania 19104, 7 Department of Computer Science and Engineering, University at Buffalo, State University of New York, Buffalo, New York 14260, \\ Departments of ${ }^{8}$ Neurology, and ${ }^{9}$ Neuroscience, The Perelman School of Medicine at The University of Pennsylvania, Philadelphia, Pennsylvania 19104
}

Recurrent seizures, which define epilepsy, are transient abnormalities in the electrical activity of the brain. The mechanistic basis of seizure initiation, and the contribution of defined neuronal subtypes to seizure pathophysiology, remains poorly understood. We performed in vivo two-photon calcium imaging in neocortex during temperature-induced seizures in male and female Dravet syndrome $(S c n 1 a+/-)$ mice, a neurodevelopmental disorder with prominent temperature-sensitive epilepsy. Mean activity of both putative principal cells and parvalbumin-positive interneurons (PV-INs) was higher in Scn1a+/- relative to wild-type controls during quiet wakefulness at baseline and at elevated core body temperature. However, wild-type PV-INs showed a progressive synchronization in response to temperature elevation that was absent in PV-INs from Scn $1 a+/-$ mice. Hence, PV-IN activity remains intact interictally in Scn $1 a+/-$ mice, yet exhibits decreased synchrony immediately before seizure onset. We suggest that impaired PV-IN synchronization may contribute to the transition to the ictal state during temperature-induced seizures in Dravet syndrome.

Key words: Dravet syndrome; epilepsy; GABAergic interneurons; Nav1.1; seizures; two-photon calcium imaging

Significance Statement

Epilepsy is a common neurological disorder defined by recurrent, unprovoked seizures. However, basic mechanisms of seizure initiation and propagation remain poorly understood. We performed in vivo two-photon calcium imaging in an experimental model of Dravet syndrome (Scn1a+/- mice) - a severe neurodevelopmental disorder defined by temperature-sensitive, treatment-resistant epilepsy_and record activity of putative excitatory neurons and parvalbumin-positive GABAergic neocortical interneurons (PV-INs) during naturalistic seizures induced by increased core body temperature. PV-IN activity was higher in Scn $1 a+/$ - relative to wild-type controls during quiet wakefulness. However, wild-type PV-INs showed progressive synchronization in response to temperature elevation that was absent in PV-INs from Scn1a+/- mice before seizure onset. Hence, impaired PV-IN synchronization may contribute to transition to seizure in Dravet syndrome.

\section{Introduction}

Epilepsy is a common neurological disorder defined by recurrent, unprovoked seizures, transient large-scale abnormalities in the

\footnotetext{
Received Oct. 3, 2019; revised Dec. 27, 2019; accepted Feb. 13, 2020.

Author contributions: S.F.M. and E.M.G. designed research; C.H.T., K.M.G., N.G., and E.M.G. performed research; C.H.T., M.V., J.N., A.S., K.M.G., P.M., S.F.M., and E.M.G. analyzed data; C.H.T., S.F.M. and E.M.G. wrote the paper.

This work was supported by an American Academy of Neurology Medical Student Summer Research Scholarship to C.H.T.; National Science Foundation (NSF) NCS-F0 Award SMA-1734795 to S.F.M.; and NIH NINDS research Grants K08 NS097633 and R01 NS110869, NSF NCS-F0 Award SMA-1734813, and the Dana Foundation David Mahoney Neuroimaging Program and the Burroughs Wellcome Fund Career Award for Medical Scientists to E.M.G. We thank Dr. Eric D. Marsh for assistance with electrocorticography, Joanna H. Mattis for comments on a prior version of this paper, Dr. Jennifer A. Kearney at Northwestern University for the generous gift of Scn1a+/- mice, and Loren Looger, GENIE Project, Janelia Research Campus of the HHMI, for distribution of GCaMP6.

The authors declare no competing financial interests.

*M.V. and J.N. contributed equally to this work.
}

electrical activity of the brain. Fundamental aspects of seizure pathophysiology remain poorly understood. The mechanism of transition from preictal to ictal state is critical to understanding the episodic yet seemingly unpredictable onset of seizures (Zhang et al., 2011). A particular focus has been placed on the activity of inhibitory GABAergic interneurons (INs) of cerebral cortex, because IN dysfunction is considered to relate to disease pathomechanisms (Bernard et al., 2000; Trevelyan and Schevon, 2013).

For example, preictal increases in IN firing or hypersynchrony of INs (Köhling et al., 2000; Beenhakker and Huguenard, 2009;

Correspondence should be addressed to Ethan M. Goldberg at goldberge@email.chop.edu or Sarah F. Muldoon at smuldoon@buffalo.edu.

https://doi.org/10.1523/JNEUROSCI.2370-19.2020

Copyright $\odot 2020$ the authors 
Lasztóczi et al., 2009; Grasse et al., 2013), might lead to failure of or reduced GABA release (Trotter et al., 2006; Zhang et al., 2012), possibly via depolarization block (Bragin et al., 1997; Ziburkus et al., 2006). Increases in IN activity could lead to chloride accumulation in target cells, rendering GABA depolarizing (Cohen et al., 2002; Khazipov et al., 2004).

However, there is little data on the activity of individual, defined subsets of neurons during seizures in humans or experimental animal models of human epilepsy. Existing data indicates significant heterogeneity but some cell-type-specific differences (Bower and Buckmaster, 2008; Truccolo et al., 2011; Toyoda et al., 2013, 2015; Fujita et al., 2014; Muldoon et al., 2015; Khoshkhoo et al., 2017; Neumann et al., 2017; Miri et al., 2018). Singleunit recordings in temporal neocortex in human patients with treatment-resistant epilepsy found that a large proportion of putative parvalbumin-positive INs (PV-INs) displayed preictal modulation of firing frequency (Truccolo et al., 2011). Singleunit recordings combined with optogenetic tagging (Lima et al., 2009) identified genetically defined subsets of neurons before and during seizures evoked by acute chemo-convulsant application in mice. Somatostatin-INs and regular spiking putative excitatory cells exhibited modest early preictal firing rate increases, with PV-INs showing an increase immediately before seizures while becoming uncoupled from ongoing rhythmic activity in the hippocampal field potential (Miri et al., 2018).

Here, we perform in vivo two-photon (2P) calcium imaging of seizures in awake, behaving experimental Dravet syndrome (DS) mice (Scnla $+/-$ mice), taking advantage of the prominent inherent temperature sensitivity of seizures in these mice (Yu et al., 2006; Ogiwara et al., 2007; Oakley et al., 2009; Miller et al., 2014; Mistry et al., 2014). DS is a neurodevelopmental disorder with onset in the first year of life due to dominant heterozygous lossof-function mutation in SCN1A encoding the voltage-gated sodium $\left(\mathrm{Na}^{+}\right)$channel subunit Nav1.1, and is characterized by treatment-resistant, temperature-sensitive epilepsy, intellectual disability, and features of autism spectrum disorder, with markedly increased mortality (Dravet, 2011; Li et al., 2011; Han et al., 2012; Scheffer, 2012; Cooper et al., 2016). Evidence suggests that PV-INs require Nav1.1 for action potential generation, forming the basis of the "interneuron hypothesis" of DS pathogenesis (Yu et al., 2006; Ogiwara et al., 2007; Tai et al., 2014; Catterall, 2018). However, the activity of defined subsets of neurons in awake, behaving Scnla + / - mice remains largely unknown.

Given that epilepsy is due to dysfunction of neuronal circuits (Kramer and Cash, 2012; Goldberg and Coulter, 2013; Paz and Huguenard, 2015), seizures are a natural application for imaging approaches including 2P calcium imaging (Rossi et al., 2018). We track PV-INs and putative excitatory pyramidal cells across seizure substates during prolonged in vivo $2 \mathrm{P}$ imaging sessions. We found that principal cell and PV-IN activity increases at baseline in awake, behaving $S c n 1 a+/-$ mice relative to wild-type. However, in Scn1a+/- mice, PV-INs showed a progressive decrease in synchronization in response to elevation of body temperature that was not observed in wild-type mice. Correspondingly, the increased synchronization between putative principal cells and PV-INs seen in wild-type mice in response to increased body temperature did not occur during transition to seizure in Scn $1 a+/-$ mice.

\section{Materials and Methods}

Experimental animals. All experiments and procedures were approved by the Institutional Animal Care and Use Committee at The Children's Hospital of Philadelphia and were conducted in accordance with the ethical guidelines of the National Institutes of Health. Both male and female mice were used in equal proportions. After weaning at P21, mice were group-housed with up to five mice per cage and maintained on a $12 \mathrm{~h} \mathrm{light/dark} \mathrm{cycle,} \mathrm{with} \mathrm{ad} \mathrm{libitum} \mathrm{access} \mathrm{to} \mathrm{food} \mathrm{and} \mathrm{water.}$

All experimental mice were either wild-type or heterozygous Scn1a+/- and on an 50:50 C57BL/6J:129S6 mixed background (Fig. $1 B)$. Mouse strains used in this study included: $S c n 1 a+/-$ mice on a 129S6.SvEvTac background (RRID:MMRRC_037107-JAX) generated by a targeted deletion of exon 1 of the Scnla gene, PV-Cre mice [B6;129P2-Pvalbtm1(cre)Arbr/J; RRID:IMSR_JAX:008069], wildtype 129S6.SvEvTac (Taconic Biosciences model \#129SVE; RRID: IMSR_TAC: 129sve), tdTomato reporter Ai14 mice (Rosa-CAG-LSLtdTomato; RRID:IMSR_JAX:007914; on a C57BL/6J background), and wild-type C57BL/6J (RRID:IMSR_JAX:000664). Heterozygous PV-Cre mice were crossed to homozygous Ail4 mice to generate Pv-Cre.tdT mice on a predominantly C57BL/6J background. Female PV-Cre.tdT double heterozygotes were then crossed to male 129S6.Scn1a+/- mice to generate Scn1a.PVCre.tdT mice and WT.PV-Cre.tdT littermate controls. The genotype of all mice was determined via PCR on DNA isolated from tail snips obtained at P7 and was reconfirmed for each mouse after mice expired because of seizure/status epilepticus or were killed after completion of the experiment. All mice used for experiments were on a near 50:50 129S6:B6J background, and Scn1a+/ - mice on this background have been shown to replicate the core phenotype of DS (Miller et al., 2014; Mistry et al., 2014). Mice were age $97.3 \pm 11.8 \mathrm{~d}$ at the time of imaging.

Stereotaxic injections and cranial window implantation. Mice used for procedures were WT or Scn 1a.PV-Cre or PV-Cre.tdt, and were typically aged 6-10 weeks at the time of surgery. Dexamethasone $5 \mathrm{mg} / \mathrm{kg}$ was delivered via intraperitoneal injection $4-6 \mathrm{~h}$ before surgery. Mice were anesthetized by inhalation of isoflurane in oxygen $(4-5 \%$ for induction, $0.8-2 \%$ for maintenance, in $0.5 \mathrm{~L} / \mathrm{min}$ oxygen). Buprenorphine-SR $(0.5-1.0 \mathrm{mg} / \mathrm{kg}$, s.c.) was injected immediately before surgery to reduce stress and surgical pain; cefazolin $500 \mathrm{mg} / \mathrm{kg}$ was injected subcutaneously for antibacterial prophylaxis. Skull surface landmarks and stereotaxic coordinates were used to identify the target area. We performed a $3 \mathrm{~mm}$ craniotomy using a handheld dental drill and removed the bone flap to expose the dura, which was opened using a microprobe. We then injected 20-40 nl of AAV9.Syn.GCaMP6s.WPRE.SV40 (Addgene, 100837) and, in selected experiments, AAV9.CAG.Flex.tdTomato.WPRE (Addgene, 51503 ) in $2-4$ sites separated by $500 \mu \mathrm{m}$ using a beveled glass micropipette attached to an injector (Nanoject II, Drummond Scientific). We then placed a cranial window composed of a $3 \mathrm{~mm}$ glass coverslip cemented to a $5 \mathrm{~mm}$ glass coverslip, which was affixed to the skull surface, along with a stainless steel head plate, using cyanoacrylate glue. The implant was then further adhered to the skull using dental cement (Metabond)

Electrocorticography. A single intracranial electrode fashioned from insulated stainless steel wire (California Fine Wire) that was bare at the tip and beveled to sharpness was placed within the cranial window area before gluing the cover glass in place. This was combined with a ground electrode in the contralateral cerebellum and reference electrode in the contralateral olfactory cortex.

Imaging. Imaging was performed using a mode-locked pulsed infrared laser (InSight, SpectraPhysics) controlled by a Pockels cell (Conoptics) on a commercial two-photon microscope (Bruker) equipped with a resonant scanner (Cambridge Technology). A 16×/0.8 NA water-immersion objective (Nikon) was used. GCaMP6f was typically imaged at $950 \mathrm{~nm}$ with a gallium arsenide phosphide photodetector (H7422-40, Hamamatsu) and tdTomato with a multi-alkali detector (R3896, Hamamatsu). Data were acquired and converted to .tif stacks for analysis.

Mice were head-fixed and free to run or rest on a treadmill fashioned from an 8 inch foam sphere housed within a custom-built acrylic chamber for passive elevation of core body temperature. Baseline activity was recorded for $\sim 4$ min before initiation of temperature elevation, which proceeded at $\sim 0.5^{\circ} \mathrm{C}$ every $1-2 \mathrm{~min}$, facilitating collection of at least $8 \mathrm{~min}$ of pre-seizure data at an elevated core body temperature (preictal), from which two 4 min epochs (early and late preictal) were selected for analysis.

For Scnla $+/-$ mice, temperature measurements during the $4 \mathrm{~min}$ early preictal and late preictal periods were $38.9 \pm 0.7^{\circ} \mathrm{C}$ and $40.4 \pm$ 
A

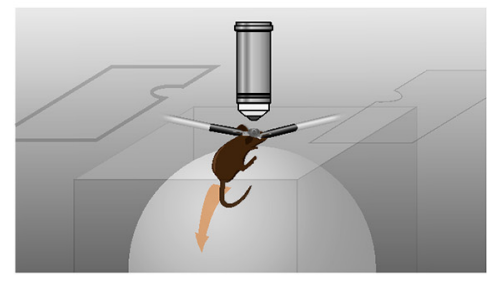

B

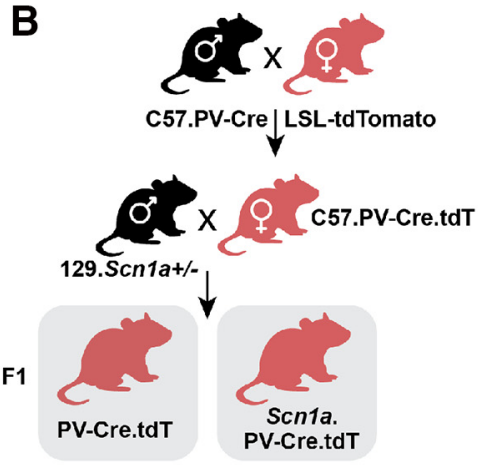

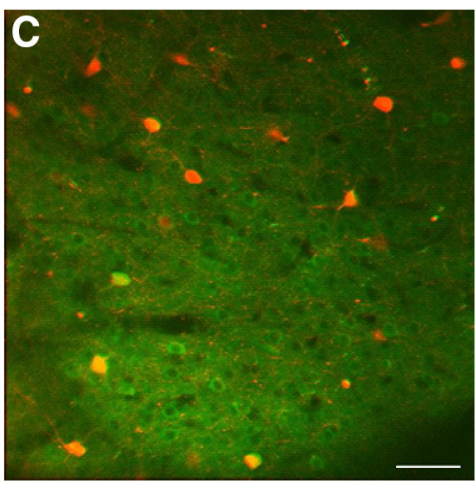

Figure 1. Schematic of the experimental approach. $\boldsymbol{A}$, Imaging apparatus. The experimental animal is head-fixed and able to run or rest on a standard spherical treadmill that sits in a custom laser-cut three-piece acrylic chamber that consists of a cube, open at the top, with a two-piece lid that contains an aperture to accommodate the microscope objective. $\boldsymbol{B}$, Breeding strategy used to produce $\mathrm{Scn} 1 \mathrm{a}+$ / - mice and age-matched wild-type littermate controls expressing tdTomato in PV-positive GABAergic INs. PV-Cre mice on a C57 background (C57.PV-Cre) were crossed to the Ai14D reporter strain (LSL-tdTomato; also on a C57 background) to produce PV-Cre.tdTomato double heterozygous mice. PV-Cre.tdTomato double heterozygous females were then crossed to Scn1a+ / - males on a 129.S6 background (129.Scn1a+/-) to produce triple transgenic Scn1a+/- mice (Scn1a.PV-Cre.tdT) and wild-type littermates. C, Labeling of PV-INs for in vivo 2P calcium imaging in Scn 1a.PV-Cre.tdT mice during seizure induction. Shown is GCaMP6f labeling of neurons in layer 2/3 sensorimotor cortex (green) including PV-INs (red) in an Scn 1a.PV-Cre.tdT mouse. The image is an average of 10 frames of $512 \times 512$ pixels acquired at $29.4 \mathrm{~Hz}$ at $2 \times$ digital zoom. Scale bar, $50 \mu \mathrm{m}$.

$0.6^{\circ} \mathrm{C}$, respectively. For wild-type mice (that did not exhibit temperatureinduced seizures), we used temperature-matched 4 min epochs, during which core body temperature was $38.0 \pm 0.4^{\circ} \mathrm{C}$ for early preictal and $40.5 \pm 0.6^{\circ} \mathrm{C}$ for late preictal.

Cell detection and extraction of neuron activity. Neuron contours were manually detected from calcium imaging movies and neuron changes in fluorescence $(\mathrm{df} / \mathrm{F})$ were extracted for each neuron. The df/F signals were de-convolved using the OASIS software package (Friedrich et al., 2017) with the partial spike threshold set at 0.3 . This resulted in a spike train for each neuron as well as a de-noised signal.

Quantification of burst and firing features. To quantify a calcium burst, we thresholded the de-noised signal at 0.1 and bursts were counted as a continuous period for which the de-noised signal remained above this threshold. We then measured the maximum height of the de-noised signal within the burst (burst amplitude), the length of the burst (burst width), the number of bursts during an imaging period (burst rate), and the number of de-convolved spikes within a burst (burst complexity). We additionally calculated the number of de-convolved spikes that occurred during an imaging period to compute a neuron's firing rate.

Synchronization. Synchronization between the activity of two neurons was assessed by calculating the maximum of the absolute value of the cross-correlation between the de-noised signal of each neuron over a lag window of $500 \mathrm{~ms}$. Cross-correlation at a lag time, $t$, was defined as follows:

$$
R(X, Y, t)=\frac{\operatorname{cov}(X, Y, t)}{\sigma_{X(0)} \sigma_{Y(0)}} .
$$

Here, the covariance between the de-noised signal of neurons $X$ and $Y$ at a lag time $t$, is divided by the product of the SD of the autocovariance of each signal at a lag time of $0\left(\sigma_{X(0)} \sigma_{Y(0)}\right)$. This normalization controls for potential differences in firing rates between populations of neurons. We computed the maximum of the absolute value of the cross-correlation over a $500 \mathrm{~ms}$ lag window to account for potential delays between firing patterns because of differences in the distance between neurons.

To assess the significance of synchronization between two pairs of neurons, we performed $95 \%$ significance testing based on comparison to surrogate datasets. To create surrogate data, partial spikes derived from OASIS were randomly distributed temporally for each neuron and within each seizure state. These spikes were then convoluted with the same exponential decay kernel used by OASIS to create a randomized de-noised signal for each neuron within a given seizure state. Note that this method preserves the firing rates of neurons, but randomizes the firing pattern. We built 1000 surrogate datasets and computed the pairwise synchronization between all neurons as described in the preceding section. Statistical significance between each pair of neurons was assessed by comparing the observed synchronization to the distribution of surrogate synchronization values at the $95 \%$ level.

Experimental design and statistical analysis. We recorded the activity of hundreds of neurons simultaneously for a $5 \mathrm{~min}$ baseline period during quiet wakefulness, followed by passive elevation of core body temperature at $\sim 0.5-1^{\circ} \mathrm{Celsius}$ per minute. Temperature elevation occurred until the mouse presented with a seizure (observed in Scn1a+/- mice only) or until body temperature reached $42.5^{\circ} \mathrm{C}$. After rejection of recording sessions contaminated by excessive motion in the $z$-plane, we included in the analysis 14 imaging sessions from 11 Scn1a+/- mice (7 Scn1a.PVCre mice and 4 Scnla+/- mice that were negative for the PV-Cre transgene) and six imaging sessions from four wild-type mice (2 WT.PV-Cre and 2 WT mice negative for the PV-Cre transgene).

To analyze the neuronal population response to temperature elevation and/or transition to seizure, we divided the preictal period into three 4 min epochs: baseline, early preictal, and late preictal. Baseline activity was defined as a 4 min window before temperature elevation was initiated. In Scn1a+/- mice, early and late preictal periods were defined as the 8 consecutive minutes of activity immediately preceding a seizure, which was consequently broken into two separate 4 min windows representing the early and late preictal periods, respectively. For wild-type mice that never had seizures, we quantified epochs of the same length at matched temperature values.

Data on the firing properties of neuronal populations was presented as violin plots as well as cumulative distribution functions. Statistical tests included a Wilcoxson rank sum test with Bonferroni correction for multiple comparisons. Statistical analysis was performed in MATLAB (MathWorks).

\section{Results}

Scn1a+/- mice exhibit robust temperature-triggered seizures amenable to two-photon imaging

Seizures in children with DS and in mouse models (Scn1a+/mice) are defined by temperature sensitivity (Oakley et al., 2009). We constructed a custom-built laser-cut acrylic chamber that contained a spherical treadmill apparatus for awake ambulation during head fixation and that was compatible with ongoing $2 \mathrm{P}$ laser scanning microscopic imaging (Fig. 1A). This system facilitated passive elevation of core body temperature for induction of hyperthermic seizures during ongoing $2 \mathrm{P}$ imaging. Infrared videography allowed for monitoring of and recording of behavioral seizures.

We used a well validated Scn1a+/- mouse line (Miller et al., 2014; Mistry et al., 2014; Hawkins et al., 2017) and performed 

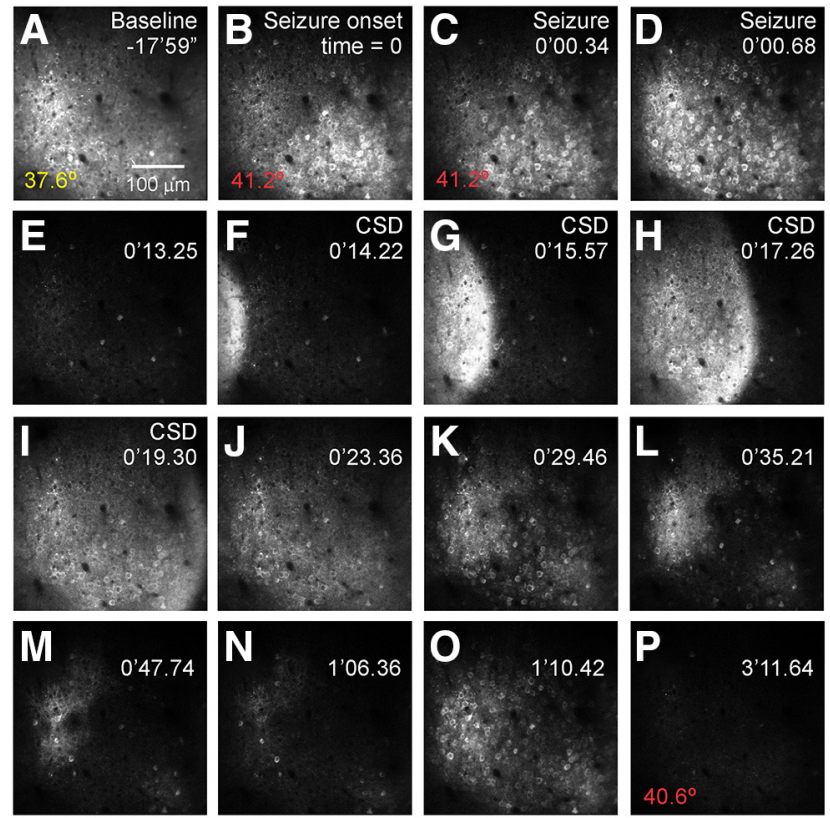

Figure 2. In vivo $2 \mathrm{P}$ calcium imaging depicts the evolution of a naturalistic seizure at cellular resolution in an awake, behaving Scn1a $+/-$ (DS) mouse. In this example, a mouse underwent passive warming to a core body temperature of $42^{\circ} \mathrm{C}$ while mobile on a spherical treadmill contained within a custom-made enclosure while head-fixed during ongoing imaging. Time during the imaging session relative to seizure onset is shown at the top right in minutes (') and seconds ("), following a $\sim 15 \mathrm{~min}$ baseline recording period) and core body temperature (bottom left) is shown. $A$, Baseline GCaMP6f fluorescence imaged at $950 \mathrm{~nm}$. B, Seizure onset, with hypersynchronous activation across the imaging field. $\boldsymbol{C}, \boldsymbol{D}$, Seizure propagation. $\boldsymbol{E}$, Post-ictal silence. $\boldsymbol{F}-\boldsymbol{L}$, Cortical spreading depolarization. $\boldsymbol{M}-\boldsymbol{P}$, Inter-ictal discharges. Data were acquired at $29.4 \mathrm{~Hz}$ at $2 \times$ digital zoom using a $16 \times$ NA 0.8 water-immersion objective (Nikon). See Movie 1.

in vivo $2 \mathrm{P}$ imaging of juvenile and young adult $S c n 1 a+/-$ mice and age-matched wild-type littermate controls using the genetically encoded calcium indicator GCaMP6f (Chen et al., 2013). There is evidence to support the existence of cell-type-specific alterations in activity patterns during the preictal period, which is hypothesized to relate to or underlie transition to seizure. In vivo $2 \mathrm{P}$ calcium imaging provides the ability to extract dynamic cellular-resolution data from specific cell types including putative excitatory cells and genetically-defined subsets of INs, using Cre driver mouse lines in which Cre recombinase is expressed under the control of cell-type-specific promoters. To identify cell-type-specific behavior in transition to seizure, we crossed Scnla + / - mice to double transgenic mice expressing the red fluorescent protein variant tdTomato under control of Cre recombinase driven by the PV promotor, labeling PV-positive fastspiking GABAergic INs (Rudy et al., 2011; Taniguchi et al., 2011), which are known to be dysfunctional in DS (Fig. 1B). Scn1a.PVCre.tdT mice ( $n=26$ seizures imaged from 21 mice, with seizures elicited in 21 of 25 mice) but not wild-type control mice $(n=7)$ readily exhibited seizures in response to passive elevation of core body temperature (Fig. 2). All experimental mice used in the study were on an $\sim 50: 50$ mixed C57BL/6J:129S6 background (see Materials and Methods; Fig. 1B).

We recorded the activity of hundreds of neurons simultaneously for at least a $4 \mathrm{~min}$ baseline period during quiet wakefulness, followed by passive elevation of core body temperature at $\sim 0.5-1^{\circ} \mathrm{C} / \mathrm{min}$. Hyperthermia elicited paroxysmal large-scale changes in imaged activity that were accompanied by behavioral manifestations consistent with seizure activity in $\operatorname{Scn} 1 a+/-$ mice

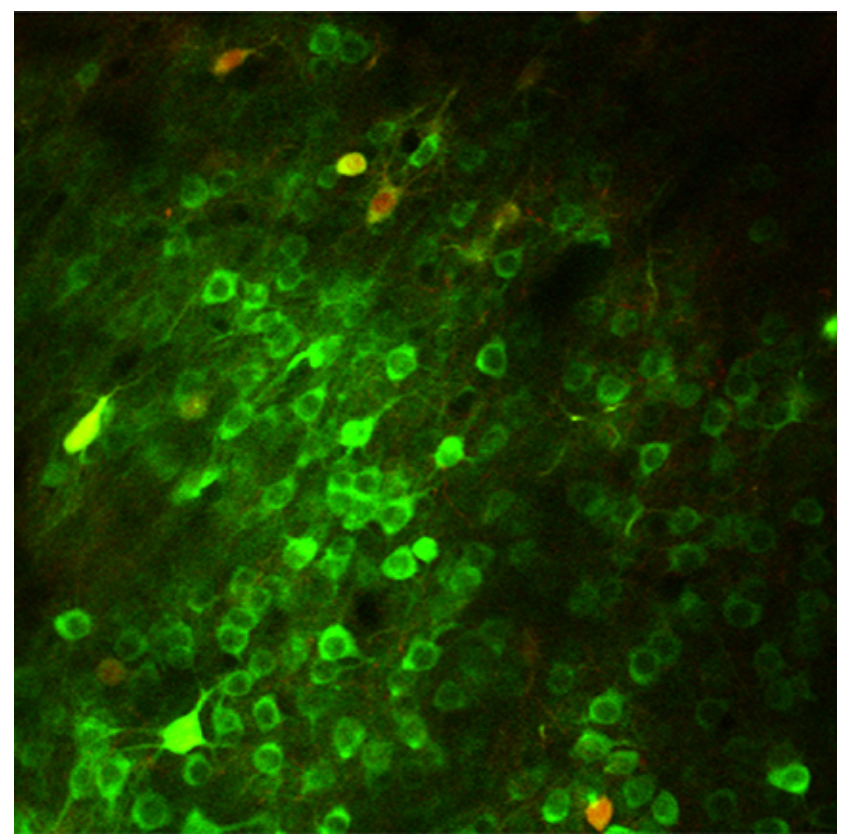

Movie 1. In vivo $2 \mathrm{P}$ calcium imaging depicted the preictal and ictal phase of a seizure in an Scn1a.PV-Cre.tdT mouse. Green, GCaMP6f; red, tdTomato in Cre-expressing cells. Data were acquired at $29.6 \mathrm{~Hz}$ with a Nikon $16 \times 0.8$ NA objective at $512 \times 512$ pixel resolution and $2 \times$ digital zoom and presented at two-times speed with 10 -frame averaging. [View online]

(Fig. 2; Movie 1). These events were characterized by large-scale hypersynchronous discharges involving most neurons in the imaged field $(89.8 \pm 3.0 \%$; mean $\pm \mathrm{SE} ; n=15$ seizures from $n=15$ mice), followed by, in all cases, a wave-like event in the fluorescence image that propagated across the imaged field at a rate of $82 \pm 21$ $\mu \mathrm{m} / \mathrm{s}$ ( $n=12$ events). We confirmed that these hypersynchronous events were indeed seizures by combining in vivo $2 \mathrm{P}$ calcium imaging with electrocorticography $(\mathrm{ECoG})$ and found that imaged events corresponded in time to the onset of electrographic seizures within hundreds of milliseconds (see Materials and Methods; Fig. 3). Analysis of these events revealed that seizures propagated in wave-like, or, occasionally, spiral, patterns (Fig. 4).

\section{Neuronal activity during transition to seizure}

As we were interested in seizure initiation, we focused our analysis on the preictal period corresponding to the transition to seizure, and quantified the activity of neurons at baseline, and during early preictal and late preictal epochs. For wild-type mice, which never had seizures (even at elevation of core body temperature to $42.5^{\circ} \mathrm{C}$ ), we quantified epochs of similar length at matched temperature values. Baseline activity was defined as a 4 min window before temperature elevation was initiated. In Scnla $+/-$ mice, early and late preictal periods were defined as the 8 consecutive minutes of activity immediately preceding a seizure, which was consequently broken into two separate $4 \mathrm{~min}$ windows representing the early and late preictal periods, respectively (Fig. 5A). Cell contours were manually detected post hoc, and changes in fluorescence over time were quantified and deconvolved to yield relative firing and bursting patterns (see Materials and Methods). Example raster plots for an Scn1a+/- and a wild-type mouse during passive temperature elevation are shown in Figure 5, $B$ and $C$.

We analyzed $n=14$ transitions to the seizure state in $n=11$ Scn1a+/- mice as well as the response to passive temperature elevation ( $n=6$ trials) in $n=4$ age-matched wild-type mice as 
control. We quantified the amplitude, width, rate, and complexity of calcium transients, as well as the relative spike rate and Methods) during the baseline ( $n=$ 1775 neurons from $n=11$ Scn1a+/mice; $n=425$ neurons from $n=4$ wildtype mice), early preictal ( $n=1837$ neurons from $n=11$ Scn1a $+/-$ mice; $n=$ 551 neurons from $n=4$ wild-type mice), and late preictal $(n=1843$ neurons from $n=11$ Scnla $+/-$ mice; $n=632$ neurons from $n=4$ wild-type mice) periods (Fig. 6). We found that burst amplitude did not change between baseline, early preictal, and late preictal periods for either wildtype or $S c n 1 a+/-$ mice yet was greater in $S c n 1 a+/-$ mice than in wild-type mice during all three epochs (Fig. 6A). In contrast, burst rate showed significant increases in both wild-type and Scnla+/mice as a function of temperature elevation. However, the burst rate in $S c n 1 a+/-$ mice was significantly higher compared with wild-type at all three time points (Fig. 6C). The increased burst rate in Scnla+/mice also corresponded to an increased burst complexity (Fig. 6D; see Materials and Methods) in Scnla+/- relative to wild-type mice at all time points. We also found that, correspondingly, the deconvolved spike rate was higher in Scn1a+/- mice compared with wild-type during temperature elevation in both wild-type and Scn1a+/- mice (Fig. 6E).

Wild-type and Scn1a+/- mice spent a similar proportion of the imaging session in quiet wakefulness versus running during the imaging sessions. Time spent running was $38.0 \pm 1.2 \%$ of the recording session for wild-type ( $n=3$ imaging sessions for $n=3$ mice for which these data were measured) versus $35.3 \pm 1.6 \%$ of the time for $\operatorname{Scn} 1 a+/-$ mice $(n=5$ imaging fields from $n=3$ mice; $p=0.93$ vs wildtype). There was no difference in the number of discrete running bouts $(2.1 \pm$ $0.5 / \mathrm{min}$ for Scn $1 a+/-$ and $2.7 \pm 0.5 / \mathrm{min}$ for wild-type; $p=0.13$ ) or in mean running speed during a bout of running $(103 \pm 20 \mathrm{~mm} / \mathrm{s}$ in wild-type and $89 \pm 30$ $\mathrm{mm} / \mathrm{s}$ in Scn $1 a+/-$ mice; $p=0.69)$. Such data indicate that there is no obvious difference in locomotion between genotypes. from de-convolved data (see Materials at all three time points, and also increased
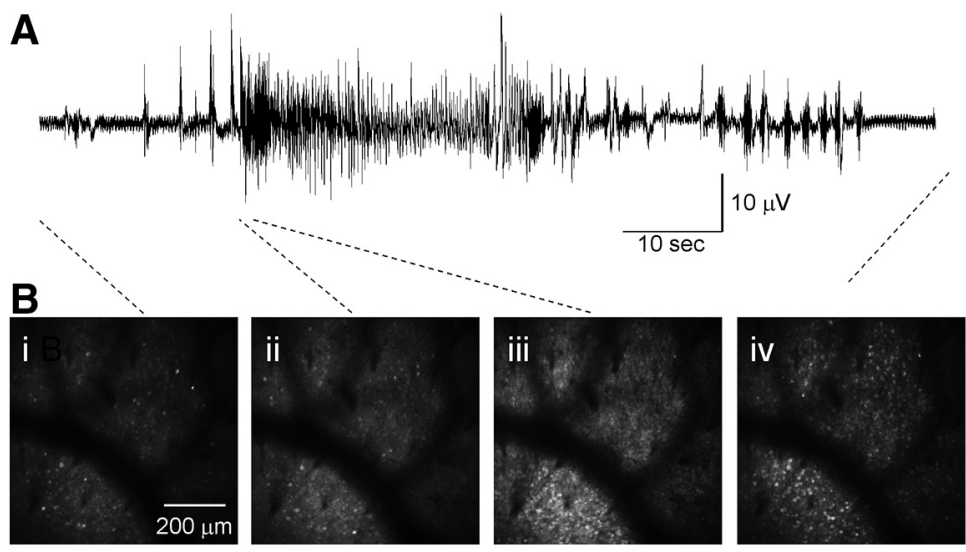

Figure 3. Combined imaging/electrophysiology during temperature-induced seizures. Local field potential recording indicates that the imaging correlates of behavioral seizures correspond to electrographic seizures. We performed ECoG (see Materials and Methods) combined with in vivo 2P imaging, with an intracortical recording electrode placed within the $3 \mathrm{~mm}$ craniotomy window. $\boldsymbol{A}$, Example recording showing a period of rhythmic spike and sharp wave activity corresponding to an electro-clinical seizure. $\boldsymbol{B}$, Simultaneous 2P imaging during the electrical recording shown above, before seizure onset $(\boldsymbol{B} \boldsymbol{i})$, at electrographic seizure onset (Bii), onset of large-scale recruitment of neuronal activity within the imaging field (Biii), and after cessation of the electrographic event (Biv).
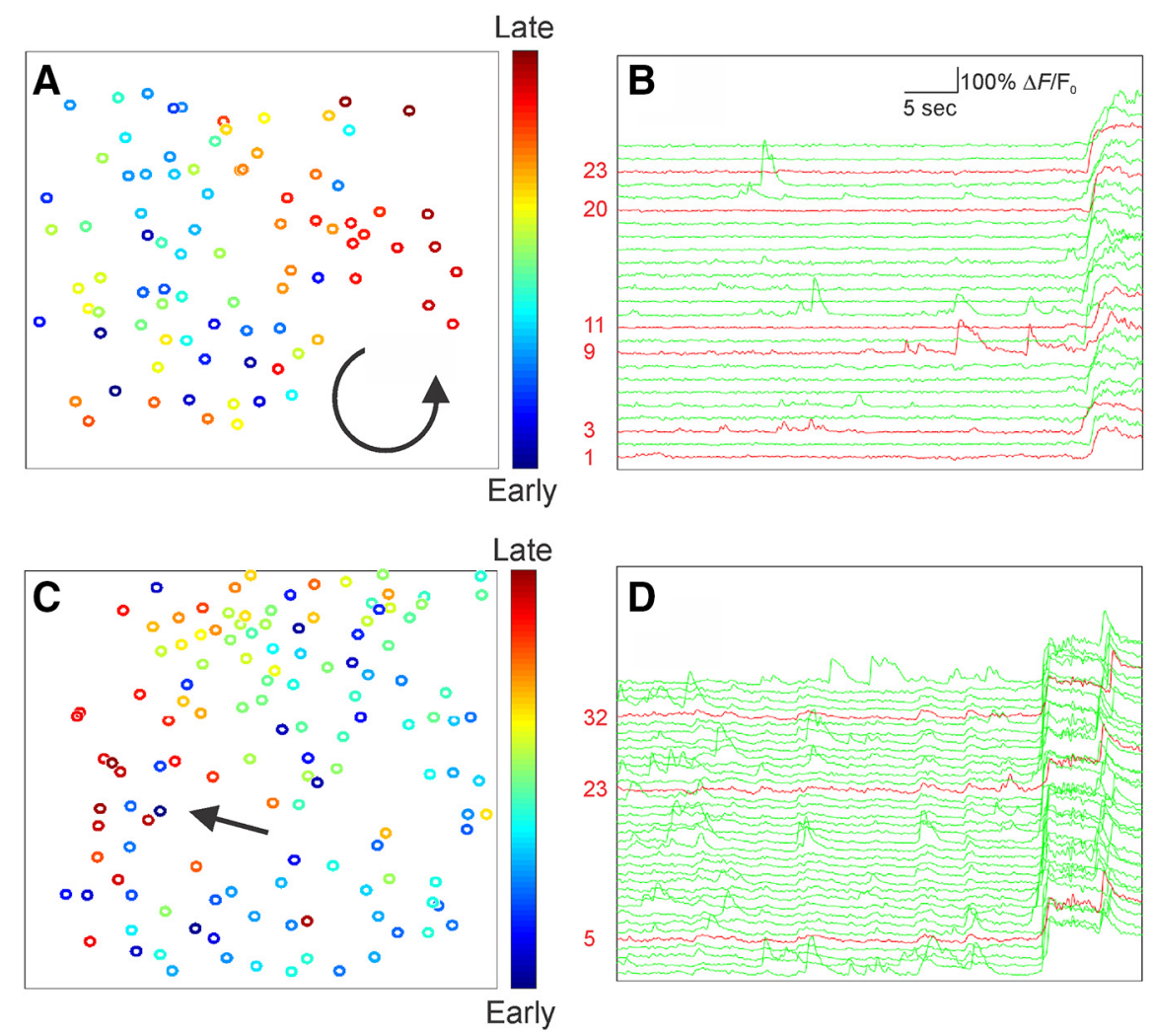

Figure 4. Analysis of cellular-resolution imaging of seizure propagation shows widespread neuronal recruitment. $\boldsymbol{A}, \boldsymbol{C}, \mathrm{Recruit}-$ ment of identified neurons during two example seizures is color-coded, with early (cool colors) and late activation (hot colors). Direction of seizure propagation is illustrated with an arrow, for a seizure with a spiral pattern $(\boldsymbol{A})$ and wave-like pattern $(\boldsymbol{C}) . \boldsymbol{B}, \boldsymbol{D}$, Selected individual $\Delta F / F_{0}$ traces for PV-INs (red) and putative excitatory cells (green) illustrating activity in the immediate preictal period.

\section{Activity of PV-positive fast-spiking}

\section{GABAergic INs at transition to seizure}

We then assessed the activity of PV-INs, because these cells have been shown to be specifically dysfunctional in developing Scn1a+/- mice (Ogiwara et al., 2007; Tai et al., 2014; De Stasi et al., 2016), although recent data suggest that PV-IN dysfunction may in fact be transient and limited to early developmental time points (Favero et al., 2018). In $n=9$ imaging sessions from $n=6$ Scn1a.PV-Cre.tdT mice and $n=4$ imaging sessions from $n=2$ wild-type mice, we analyzed the firing properties of PV-INs during the baseline ( $n=88$ neurons from $n=6 \operatorname{Scn} 1 a+/-$ mice; $n=$ 32 neurons from $n=2$ wild-type mice), early preictal ( $n=84$ neurons from $n=6 \operatorname{Scn} 1 a+1-$ mice; $n=27$ neurons from $n=2$ 
A

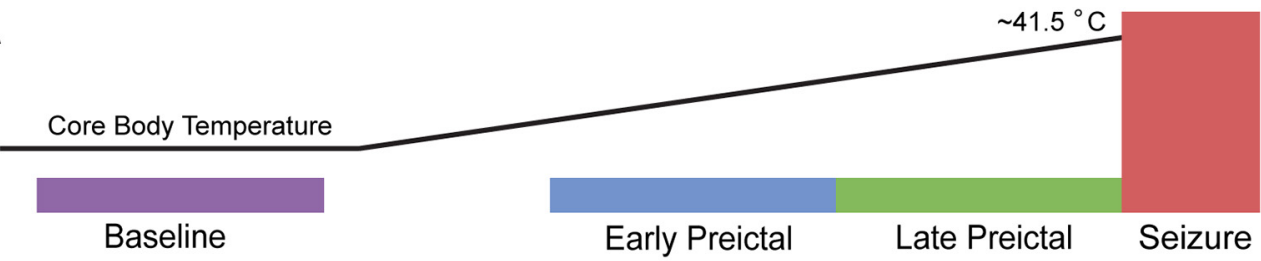

B
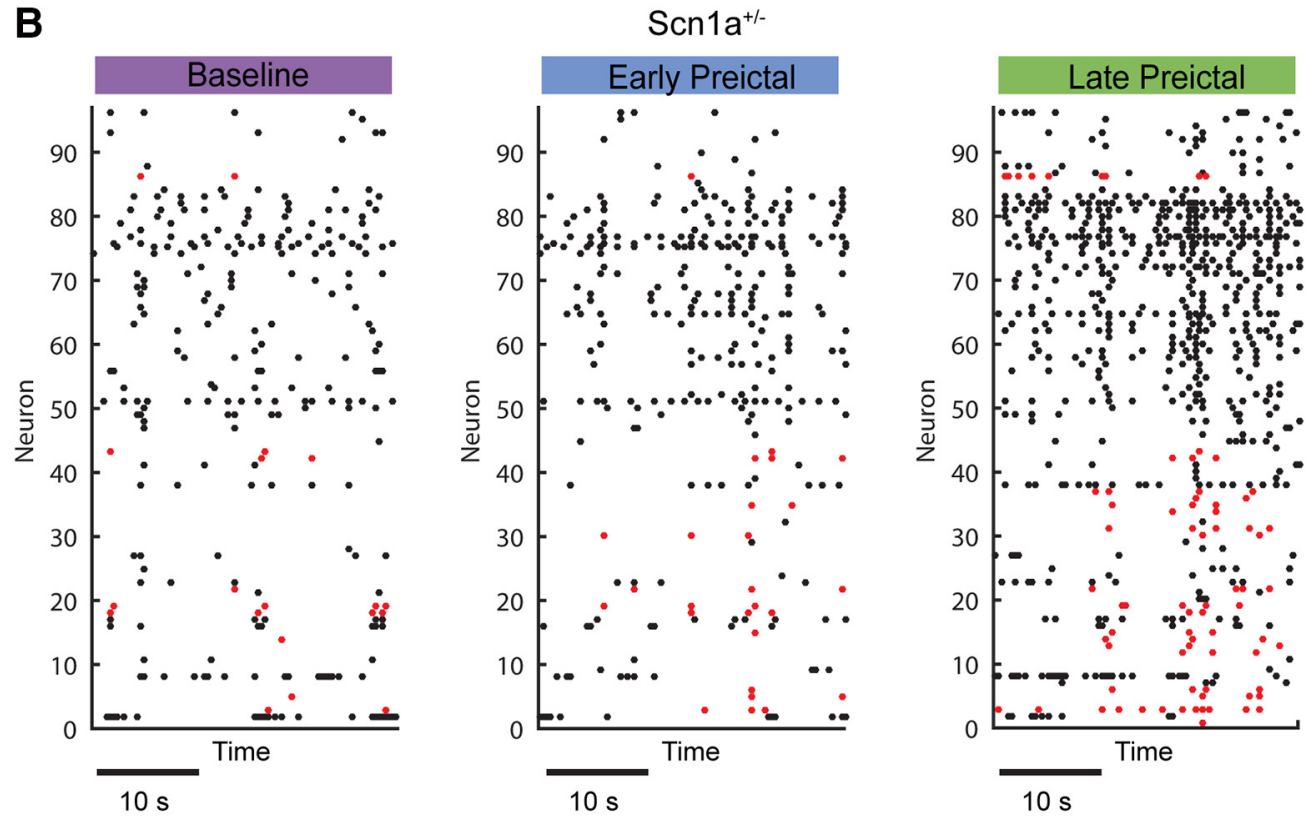

C
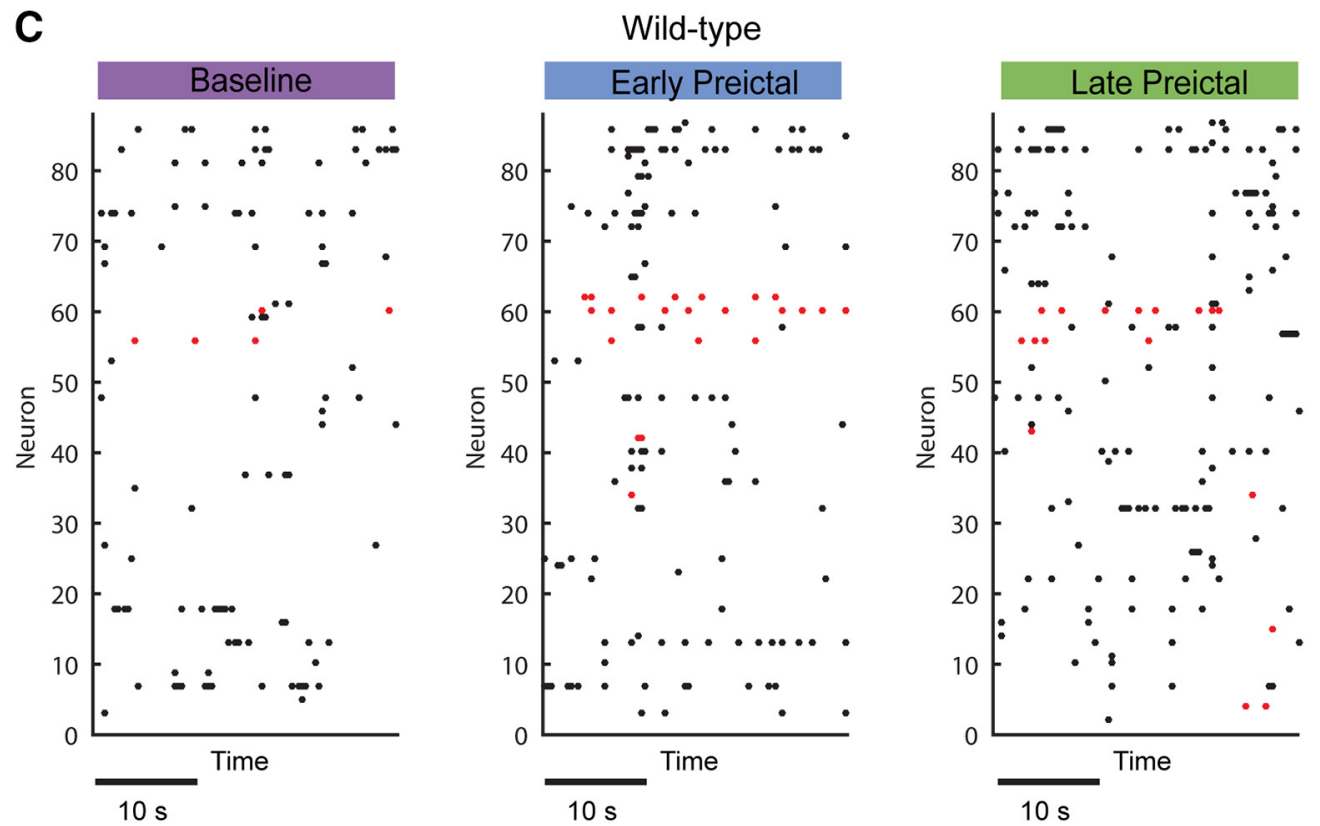

Figure 5. Neural activity during seizure initiation and propagation. $\boldsymbol{A}$, Baseline activity is extracted from a 4 min window before temperature elevation. The preictal period (at least 8 min immediately preceding the seizure in $\mathrm{Scn} 1 \mathrm{a}+/$ - mice, or a temperature matched epoch in wild-type mice) is broken into two 4 min segments (early and late preictal). $\boldsymbol{B}, \boldsymbol{C}$, Raster plots of $30 \mathrm{~s}$ of neuronal activity of putative principal cells (black) and PV-INs (red) from an Scn1a+/- $(\boldsymbol{B})$ and a wild-type mouse ( $($ ) during temperature elevation, that, in $\mathrm{Scn} 1 a+/-$ mice, leads to a seizure.

wild-type mice), and late preictal ( $n=79$ neurons from $n=6$ Scn $1 a+/-$ mice; $n=28$ neurons from $n=2$ wild-type mice) periods. As seen in Figure 7, the evolution of firing properties of PV-INs showed similar results to the general population. Interestingly, we found that the firing rate of PV-INs was higher in juvenile/young adult $S c n 1 a+/-$ mice compared with age-matched controls across conditions (Fig. 7E). Addi- tionally, we found a more dramatic increase in PV-IN spike rate with increasing temperature in $S c n 1 a+/-$ mice compared with wild-type. Corresponding trends were seen in the burst rate and complexity.

Data presented thus far indicate that the initiation of naturalistic seizures in awake, behaving mice, in a well validated experimental model of a prominent epilepsy syndrome, does 
A
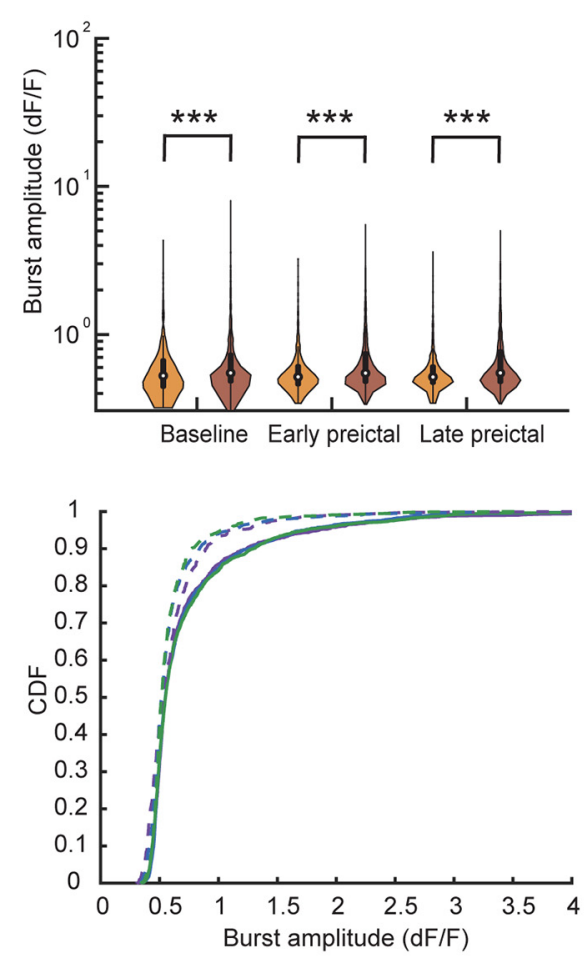

D
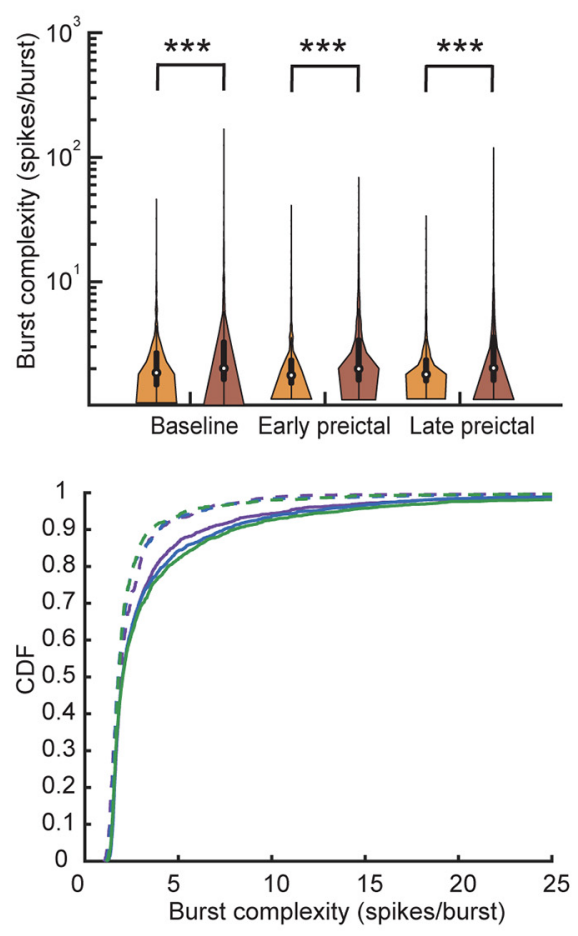

B
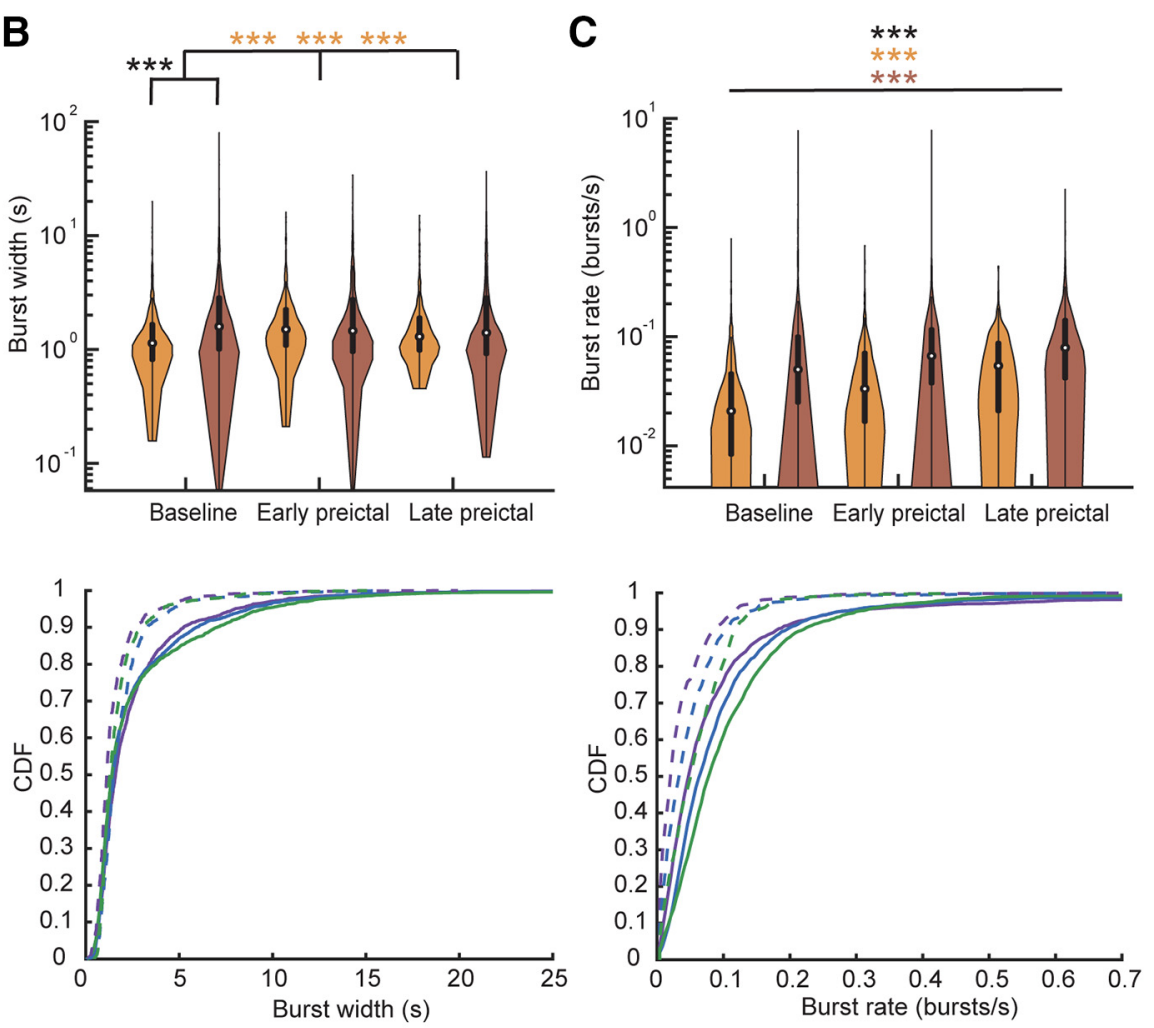

E
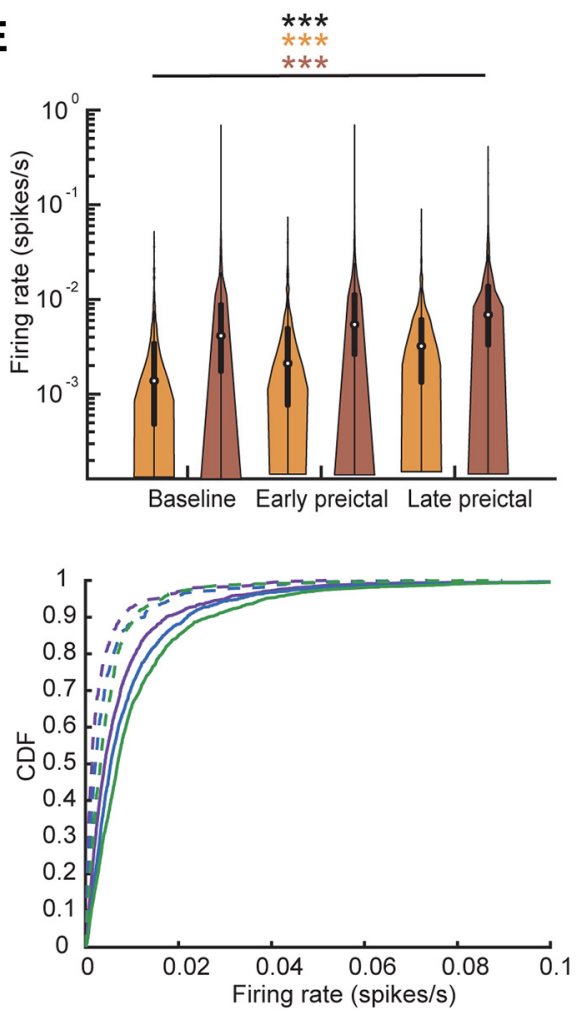
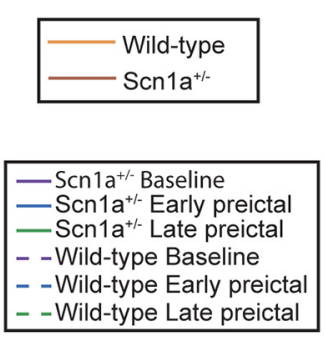

Comparison between:

* Wild-type and Scn1 $1 a^{+/-}$

* Wild-type and Wild-type

* Scn1 $\mathrm{a}^{+/-}$and Scn $1 \mathrm{a}^{+/ \text {- }}$

$* * * \quad \mathrm{p}<0.001$

** $\quad p<0.01$

* $\quad p<0.05$

Figure 6. Neuronal firing properties. Burst amplitude $(\boldsymbol{A})$, burst width $(\boldsymbol{B})$, burst rate $(\boldsymbol{C})$, burst complexity $(\boldsymbol{D})$, and de-convolved firing rate $(\boldsymbol{E})$ for wild-type and $S \mathrm{Cn} 1 \mathrm{a}+/-$ mice during baseline, early, and late preictal periods. Top, Violin plots express the shape of the distribution, white circles indicate the median, and black lines represent the 25-75\% quartiles. Bottom, Corresponding cumulative distribution function (CDF) for the above data. Statistical tests were performed using a Wilcoxson rank sum test and Bonferroni corrected for multiple comparisons. For $C$ and $E$, all pairwise comparisons were statistically significant after multiple comparison correction.

not involve an impairment of PV-IN firing, but instead suggests a progressive increase of activity in both excitatory neurons and PV-INs. In fact, PV-INs exhibit increased activity in Scn1a+/- compared with wild-type mice and their activity is enhanced with temperature elevation preictally. How this might impact global brain dynamics and lead to the initiation of a seizure is not clear, but argues against preictal failure of PV-IN spiking in the lead-in to temperature-induced 
A

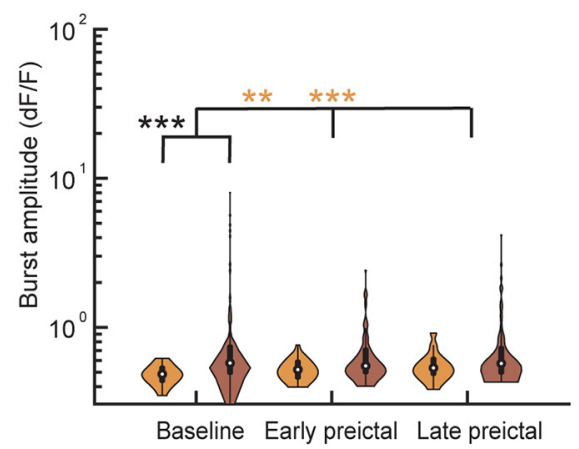

D

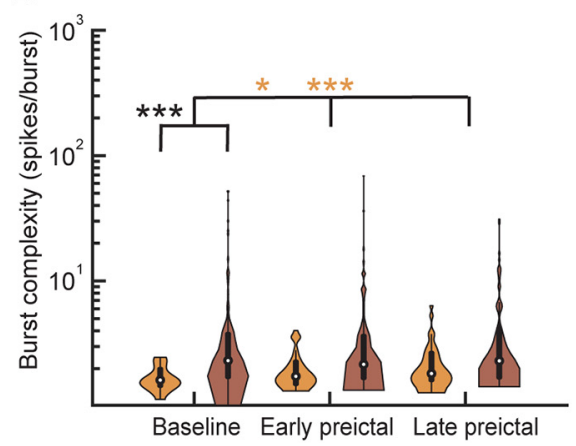

B

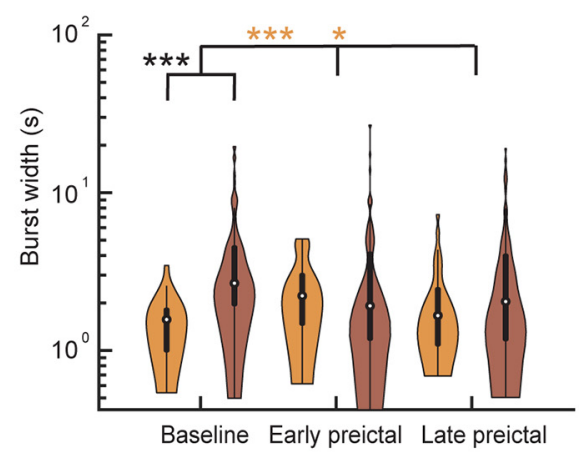

E

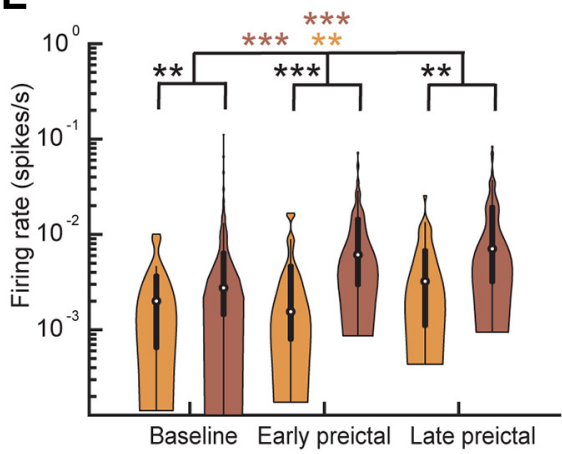

C
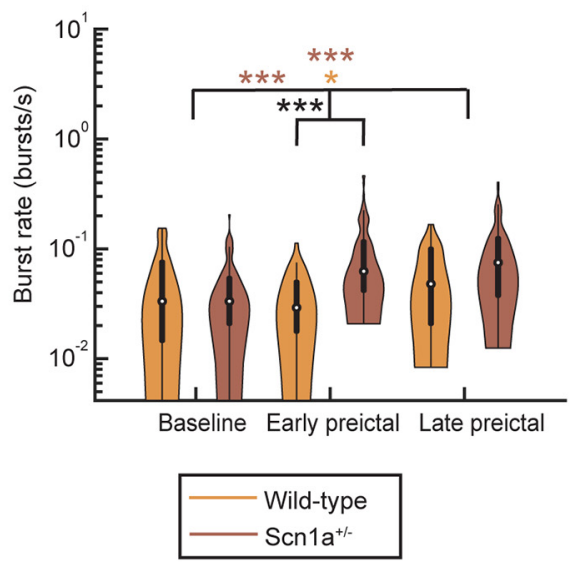

Comparison between:

* Wild-type and Scn1a ${ }^{+-}$

* Wild-type and Wild-type

* Scn1 $1 a^{+/-}$and Scn1 $1 a^{+/-}$

$\star * * \quad p<0.001$

$* * \quad p<0.01$

* $\quad p<0.05$

Figure 7. PV-IN activity profiles. Burst amplitude $(\boldsymbol{A})$, burst width $(\boldsymbol{B})$, burst rate $(\boldsymbol{C})$, burst complexity $(\boldsymbol{D})$, and de-convolved firing rate $(\boldsymbol{E})$ for PV-INs in wild-type and Scn 1a+/- mice during baseline, early, and late preictal periods. Violin plots express the shape of the distribution, white circles indicate the median, and black lines represent the $25-75 \%$ quartiles. Statistical tests were performed using a Wilcoxson rank sum test and Bonferroni corrected for multiple comparisons.

seizures in Scn1a+/- mice as a mechanism of transition to seizure.

\section{Alterations in neuronal synchronization precedes seizures in Scn1a+/- mice}

We next considered whether there were changes in the synchronization of putative excitatory neurons, of INs, and between excitatory neurons and INs, in wild-type versus $S c n l a+/-$ mice, and across seizure states. We calculated the absolute value of the maximum cross-correlation between pairs of neurons over a lag window of $500 \mathrm{~ms}$ during each epoch and tracked the fraction of significantly correlated neurons (Fig. 8; Materials and Methods). Whereas excitatory neuron synchrony increased from baseline $($ median $=0.15)$ to late preictal periods $($ median $=0.25)$ in wild-type mice (Wilcoxson rank sum test, $p \ll 0.001$; Fig. $8 A$ ), we observed a slight decrease in the synchronization of Scn1a $+/-$ excitatory cells (baseline median $=0.14$; late preictal median $=0.13$; Wilcoxson rank sum test, $p \ll 0.001$, Fig. $8 A$ ). However, we found that there was desynchronization of PV-IN activity between baseline and the late preictal state in Scnla + mice $($ Scn $1 a+/-$ PV-IN baseline median $=0.29$; late preictal median $=0.21$; Wilcoxson rank sum test, $p=0.002$ ), with no change in PV-IN synchronization in wild-type mice in response to elevation of body temperature (Fig. 8B). We found that synchrony between PV-INs and putative excitatory neurons was higher in Scn1a+/- mice at baseline compared with wild-type, but did not increase with temperature elevation and transition across seizure substates; in contrast, PV-IN-excitatory neuron synchrony increased with temperature elevation in wild-type mice (Fig. 8C). These results are supported by the identified differences in the fraction of pairs that exhibited significant correla- tion, which follows similar trends to the synchronization values across seizure states (Fig. 8).

Thus, we observe multiple differences in synchronization properties during temperature elevation in Scnla $1-$ - mice that were not observed in wild-type mice. First, PV-INs exhibit a progressive decline in synchronization preictally in $\mathrm{Scn} 1 a+/-$ mice. Second, putative excitatory cells in Scn1a+/- mice do not exhibit the increased synchronization seen in wild-type mice during temperature elevation. Finally, the enhanced synchronization between PV-INs and principal cells observed in wild-type mice in response to temperature elevation did not occur in Scnla+/mice. Hence, the data presented here supports the conclusion that decreased synchronization between excitatory and inhibitory populations in Scn1a+/ - mice relative to wild-type controls may relate to transition to seizure.

\section{Discussion}

Here, we performed in vivo $2 \mathrm{P}$ calcium imaging of naturalistic seizures in awake, behaving mice that model the prominent neurodevelopmental disorder of DS (Scnla+/- mice).

Imaging is proving to be increasingly applicable to the study of seizures and epilepsy (Rossi et al., 2018). A range of imaging approaches have been undertaken in recent years in the epilepsy field, including wide-field epifluorescence imaging of geneticallyencoded calcium indicators (Rossi et al., 2017; Steinmetz et al., 2017), fast confocal and epifluorescence imaging in zebrafish (Rosch et al., 2018; Liu and Baraban, 2019), "miniscope" imaging (Berdyyeva et al., 2016), fiber photometry (Khoshkhoo et al., 2017; Zhang et al., 2019), and 2P imaging of epileptiform discharges (Muldoon et al., 2015) and of spontaneous absence seizures (Meyer et al., 2018) in rodent models. This work represents 


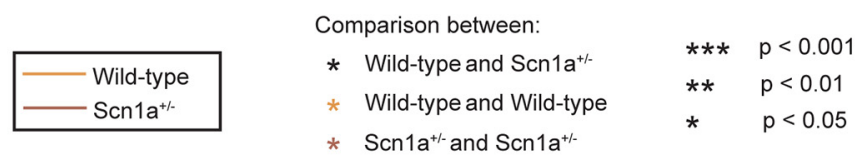

A
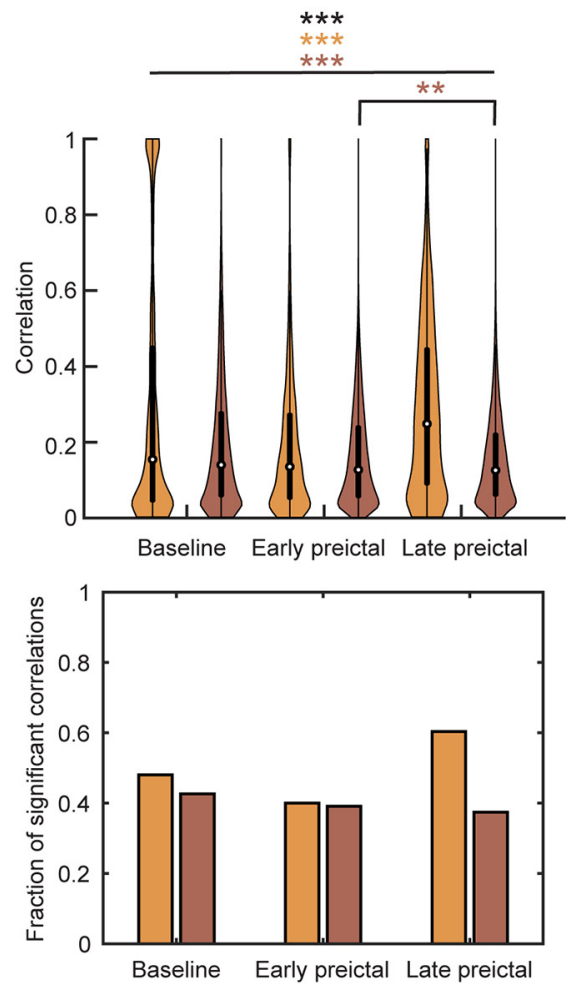

B
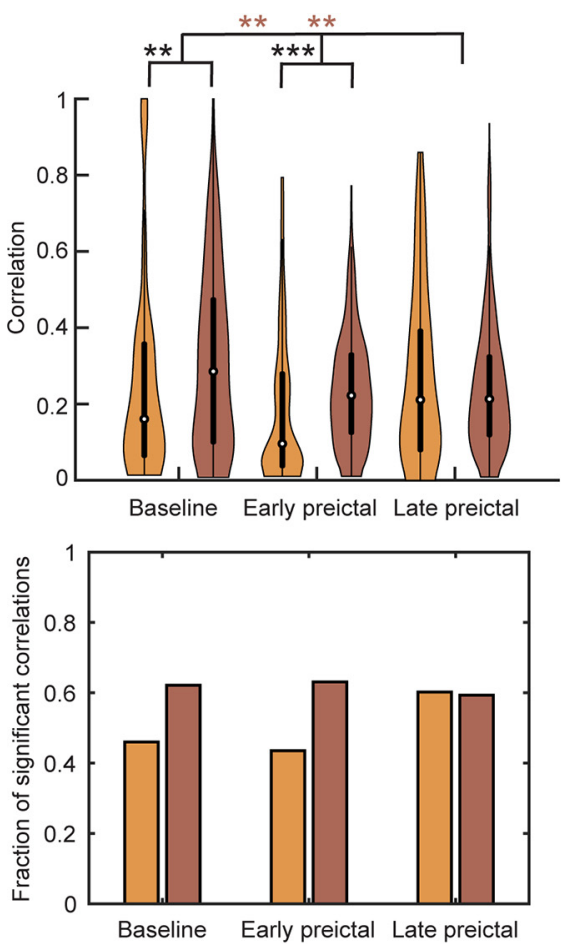

C Between pyramidal and PV cells
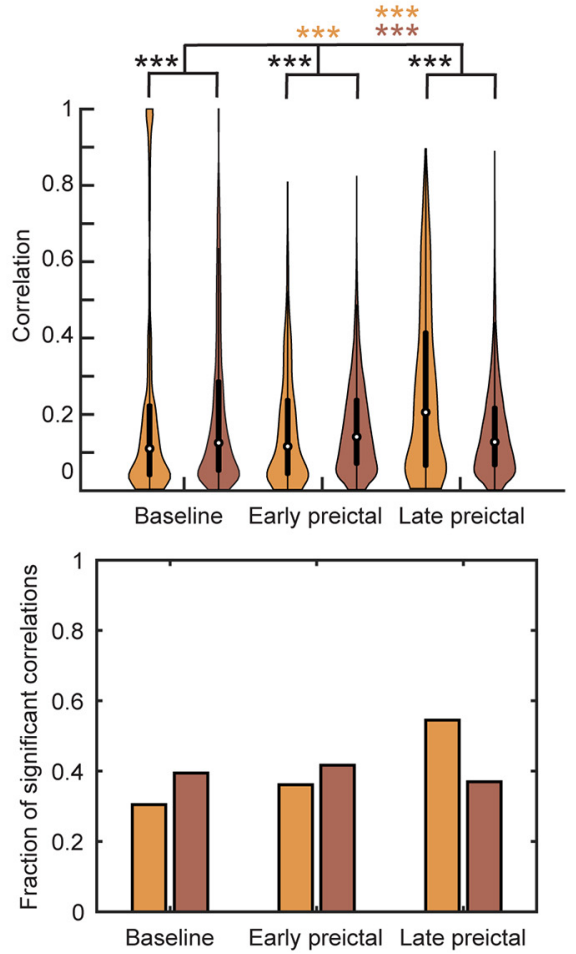

Figure 8. Neuron synchronization. Synchronization (top) and the fraction of significantly correlated pairs of neurons (bottom) was assessed using the maximum of the absolute value of cross-correlation over a $500 \mathrm{~ms}$ window between pairwise spike patterns within excitatory cells $(\boldsymbol{A})$, within PV-INs ( $\boldsymbol{B})$, and between excitatory cells and PV-INs ( $\boldsymbol{C}$ ). Violin plots express the shape of the distribution, white circles indicate the median, and black lines represent the $25-75 \%$ quartiles. Statistical tests comparing synchronization distributions were performed using a Wilcoxson rank sum test and Bonferroni corrected for multiple comparisons. A, All comparisons are significant at $p<0.001$ with the exception of between early and late preictal periods in Scn $1 a+/-$ mice, which is significant at $p<0.01$. The fraction of significant pairs of synchronized neurons was computed by comparison to surrogate datasets at the $95 \%$ level.

one of the first in vivo $2 \mathrm{P}$ imaging studies in an experimental mouse model of an early infantile/developmental and epileptic encephalopathy. We record the activity of defined subsets of neurons in awake, behaving $S c n 1 a+/-$ mice, and successfully perform in vivo $2 \mathrm{P}$ imaging during convulsive seizures in epileptic mice. As such, this study provides novel, cellular-level information on the activity of defined subsets of neurons during transition to seizure in experimental animals with established, chronic epilepsy.

Wenzel et al. (2017) used in vivo 2P calcium imaging to study seizure-like events induced by focal application of 4-aminopyridine (4AP) and picrotoxin. In this study, seizures were induced in normal (non-epileptic) experimental animals (Wenzel et al., 2017). Both 4-AP (via blockade of Kv3 channels in PV-INs; Erisir et al., 1999; Goldberg et al., 2005) and picrotoxin (as a non-competitive blocker of $\mathrm{GABA}_{\mathrm{A}}$ receptors) impairs inhibition, which is a likely mechanism whereby these agents induce seizure-like activity. A major advantage of this approach, however, is the ability to repeatedly induce ictal events, which allowed for the determination that such epileptiform activity propagated across the neocortex in a stereotypical, reproducible pattern. Although we did record more than one seizure from a small number of experimental subjects, this was on different days, and included sampling from different fields of view. A high mortality rate $(>30 \%)$ during temperature-induced seizures precluded the ability to study any consistency of seizure propagation patterns in a given animal. Furthermore, because spontaneous convulsive seizures in these mice are infrequent (1-2 per day; Anderson et al., 2014; Hawkins et al., 2017; Baker et al., 2018), it was not possible to perform a comparison of spontaneous versus temperature-induced seizures.

The "interneuron hypothesis" is the leading theory of DS pathogenesis (Catterall, 2018). However, much of these data derives from in vitro preparations. Mouse models of DS (Scn1a+/mice) recapitulate salient features of the human condition, including temperature-sensitive seizures, treatment-resistant epilepsy, autism spectrum disorder, ataxia, and sudden death (Yu et al., 2006; Ogiwara et al., 2007; Mistry et al., 2014). Accumulated evidence from electrophysiological recordings in dissociated neurons or acute brain slices prepared from $S c n 1 a+/-$ mice as well as from developing INs generated from human induced pluripotent stem cells from human patients with DS suggests that GABAergic INs are more severely impaired (Jiao et al., 2013; Sun et al., 2016), although increased $\mathrm{Na}^{+}$current has been observed in excitatory cells in certain model systems (Liu et al., 2013; Mistry et al., 2014). In particular, electrophysiological recordings in acute brain slices prepared from $S c n 1 a+/-$ mice indicate that PV-INs rely on Nav1.1 for action potential generation and hence are dysfunctional in DS (Ogiwara et al., 2007; Tai et al., 2014; De 
Stasi et al., 2016; Favero et al., 2018). A single prior study performed in vivo 2P-guided cell attached recordings from PV-INs in anesthetized Scnla+/- mice and found that firing rates were normal during the ketamine-induced slow oscillation (De Stasi et al., 2016). Our data reporting the activity of defined subsets of neurons in awake, behaving Scn1a+/- mice extends the state of existing knowledge in the field. Such data suggest that mean activity is increased in PV-INs relative to wild-type controls during quiet wakefulness, and is further increased with temperature elevation in juvenile/early adult $S c n 1 a+/-$ mice. This finding is consistent with recent data showing that the previously reported deficits in PV-IN excitability in Scnla +/- mice are in fact transient and limited to early developmental time points.(Favero et al., 2018).

However, that there was desynchronization of PV-IN activity between baseline and the preictal state in Scnla+/- mice, with no change in PV-IN synchronization in wild-type mice in response to similar elevation of body temperature, suggests that PV-INs do remain dysfunctional in Scn1a+/- mice in vivo. The basis of this difference is unclear, but could relate to chronic structural and molecular alterations in PV-INs that could influence PV-IN synaptic transmission and/or gap junctional coupling, which in turn could lead to impairments in the known function of PV-INs in the modulation of rhythmic and oscillatory activity in the cerebral cortex (Bartos et al., 2007; Cardin et al., 2009; Sohal et al., 2009).

We found that synchrony between PV-INs and putative excitatory neurons was higher in Scnla+/- mice at baseline compared with wild-type, but decreased with temperature elevation and transition across seizure substates; in contrast, PV-IN-excitatory neuron synchrony increased with temperature elevation in wild-type mice. These data suggest that, at baseline, PV-IN activity is increased and is recruited by temperature elevation as in wild-type, but becomes desynchronized between INs and with excitatory cells, which may relate to transition to seizure.

That there was no temperature-induced increase in PV cell synchrony with increased temperature in Scnla+/- mice yet hypersynchrony relative to wild-type mice at baseline was unexpected. One explanation for this finding is that increased baseline PV-IN synchrony in Scnla+/- mice is compensatory, because PV-INs are known to undergo compensatory/developmental alterations in Scnla+/- mice (Favero et al., 2018). However, the temperature-induced recruitment of PV-IN synchronization fails in Scnla+/- mice. Perhaps increased core body temperature shifts the system toward seizure, but temperature-dependent recruitment of inhibition acts to stabilize cerebral cortical circuit excitability under normal conditions. However, in Scnla+/mice, this does not occur, which may relate to the mechanism of temperature-induced seizure.

In this study, we focused our analysis on the transition to seizure. Future work may further explore the cellular architecture and dynamics of seizures themselves. We did find that seizure onset was associated with hypersynchronous discharge of most neurons (but see below). Interestingly, we observed that seizure propagation sometimes occurred in the form of what appeared to be spiral waves (Huang et al., 2010; Viventi et al., 2011). Similar events were observed in a recent study by Rossi et al. (2017) toward the end of seizures.

There are a number of limitations of this work. For technical reasons, our data acquisition was limited to superficial layers (layer 2/3) of primary sensorimotor cortex. Whether our findings generalize to other layers and across brain regions is unclear. Second, it is well known that the relationship of number of action potentials and fluorescence response differs between excitatory pyramidal neurons and PV-INs (Chen et al., 2013), such that signals recorded in PV-INs here may preferentially reflect bursting. Although we could not quantify the absolute number(s) of action potentials represented by the imaged changes in fluorescence, we can compare the relative signals between experimental groups. Our prior data showed that PV-IN action potential halfwidth in neocortical PV-INs in acute brain slice is identical between wild-type and Scn1a+/- mice at P35-P56 (0.39 $\pm 0.03 \mathrm{~ms}$ in PV-INs from Scn1a.PV-Cre.tdTomato mice and $0.37 \pm 0.05$ $\mathrm{ms}$ from PV-INs from age-matched wild-type littermate controls; Favero et al., 2018), suggesting that spike-evoked calcium influx should also be similar between genotypes. This study focused on PV-INs and did not assess the activity of other subtypes of neocortical GABAergic inhibitory INs. PV-INs could be reliably identified by tdTomato expression in Scn1a.PV-Cre and WT.PV-Cre mice. However, the AAV vector selected for use here was serotype 9 and drove GCaMP6 expression under control of the hSyn 1 promoter; hence, a small subset of what are considered putative excitatory cells may be non-PV-expressing INs. However, this likely does not change our conclusions regarding the preictal activity of PV-INs in Scnla+/- versus wild-type animals. Finally, due to the prolonged nature of our recording periods and some progressive image instability that we attribute to the temperature elevation process, we were not able to track the same neurons throughout all three imaging epochs in all recording sessions.

It is possible that temperature dynamics and cerebral blood flow were altered due to use of a water-immersion objective and cranial window preparation (Roche et al., 2019). We performed simultaneous brain tissue-core body temperature measurements in craniotomized mice and found that brain temperature was not statistically different from core body temperature during temperature elevation (data not shown). However, we were unable to perform similar measurements of brain tissue beneath the implanted glass imaging window during imaging with a waterimmersion objective. It is possible that our results might be influenced by alterations in cerebral blood flow and partial pressure of oxygen in the tissue secondary to the experimental approach, although this did not differ between wild-type and Scnla+/mice. Future experiments using a thin skull preparation may be able to further inform this issue.

Finally, it is highly likely that we were imaging seizure propagation rather than seizure initiation. DS is a multifocal epilepsy and seizures likely initiate from various sites throughout the neocortex and hippocampus (Liautard et al., 2013). Combined imaging with ground-truth electrophysiological data as well as using the latest generation of improved calcium indicators could provide additional information on the role of PV-INs in seizure initiation and propagation in DS and other epilepsies.

\section{References}

Anderson LL, Thompson CH, Hawkins NA, Nath RD, Petersohn AA, Rajamani S, Bush WS, Frankel WN, Vanoye CG, Kearney JA, George AL Jr (2014) Antiepileptic activity of preferential inhibitors of persistent sodium current. Epilepsia 55:1274-1283.

Baker EM, Thompson CH, Hawkins NA, Wagnon JL, Wengert ER, Patel MK, George A Jr, Meisler MH, Kearney JA (2018) The novel sodium channel modulator GS-458967 (GS967) is an effective treatment in a mouse model of SCN8A encephalopathy. Epilepsia 59:1166-1176.

Bartos M, Vida I, Jonas P (2007) Synaptic mechanisms of synchronized gamma oscillations in inhibitory interneuron networks. Nat Rev Neurosci 8:45-56.

Beenhakker MP, Huguenard JR (2009) Neurons that fire together also con- 
spire together: is normal sleep circuitry hijacked to generate epilepsy? Neuron 62:612-632.

Berdyyeva TK, Frady EP, Nassi JJ, Aluisio L, Cherkas Y, Otte S, Wyatt RM, Dugovic C, Ghosh KK, Schnitzer MJ, Lovenberg T, Bonaventure P (2016) Direct imaging of hippocampal epileptiform calcium motifs following kainic acid administration in freely behaving mice. Front Neurosci 10:53.

Bernard C, Cossart R, Hirsch JC, Esclapez M, Ben-Ari Y (2000) What is GABAergic inhibition? How is it modified in epilepsy? Epilepsia 41: S90-S95.

Bower MR, Buckmaster PS (2008) Changes in granule cell firing rates precede locally recorded spontaneous seizures by minutes in an animal model of temporal lobe epilepsy. J Neurophysiol 99:2431-2442.

Bragin A, Penttonen M, Buzsáki G (1997) Termination of epileptic afterdischarge in the hippocampus. J Neurosci 17:2567-2579.

Cardin JA, Carlén M, Meletis K, Knoblich U, Zhang F, Deisseroth K, Tsai LH, Moore CI (2009) Driving fast-spiking cells induces gamma rhythm and controls sensory responses. Nature 459:663-667.

Catterall WA (2018) Dravet syndrome: a sodium channel interneuronopathy. Curr Opin Physiol 2:42-50.

Chen TW, Wardill TJ, Sun Y, Pulver SR, Renninger SL, Baohan A, Schreiter ER, Kerr RA, Orger MB, Jayaraman V, Looger LL, Svoboda K, Kim DS (2013) Ultrasensitive fluorescent proteins for imaging neuronal activity. Nature 499:295-300.

Cohen I, Navarro V, Clemenceau S, Baulac M, Miles R (2002) On the origin of interictal activity in human temporal lobe epilepsy in vitro. Science 298:1418-1421.

Cooper MS, Mcintosh A, Crompton DE, McMahon JM, Schneider A, Farrell K, Ganesan V, Gill D, Kivity S, Lerman-Sagie T, McLellan A, Pelekanos J, Ramesh V, Sadleir L, Wirrell E, Scheffer IE (2016) Mortality in Dravet syndrome. Epilepsy Res 128:43-47.

De Stasi AM, Farisello P, Marcon I, Cavallari S, Forli A, Vecchia D, Losi G, Mantegazza M, Panzeri S, Carmignoto G, Bacci A, Fellin T (2016) Unaltered network activity and interneuronal firing during spontaneous cortical dynamics in vivo in a mouse model of severe myoclonic epilepsy of infancy. Cereb Cortex 26:1778-1794.

Dravet C (2011) The core Dravet syndrome phenotype. Epilepsia 52:3-9.

Erisir A, Lau D, Rudy B, Leonard CS (1999) Function of specific K(+) channels in sustained high-frequency firing of fast-spiking neocortical interneurons. J Neurophysiol 82:2476-2489.

Favero M, Sotuyo NP, Lopez E, Kearney JA, Goldberg EM (2018) A transient developmental window of fast-spiking interneuron dysfunction in a mouse model of Dravet syndrome. J Neurosci 38:7912-7927.

Friedrich J, Zhou P, Paninski L (2017) Fast online deconvolution of calcium imaging data. PLoS Comput Biol 13:e1005423.

Fujita S, Toyoda I, Thamattoor AK, Buckmaster PS (2014) Preictal activity of subicular, CA1, and dentate gyrus principal neurons in the dorsal hippocampus before spontaneous seizures in a rat model of temporal lobe epilepsy. J Neurosci 34:16671-16687.

Goldberg EM, Coulter DA (2013) Mechanisms of epileptogenesis: a convergence on neural circuit dysfunction. Nat Rev Neurosci 14:337-349.

Goldberg EM, Watanabe S, Chang SY, Joho RH, Huang ZJ, Leonard CS, Rudy B (2005) Specific functions of synaptically localized potassium channels in synaptic transmission at the neocortical GABAergic fast-spiking cell synapse. J Neurosci 25:5230-5235.

Grasse DW, Karunakaran S, Moxon KA (2013) Neuronal synchrony and the transition to spontaneous seizures. Exp Neurol 248:72-84.

Han S, Tai C, Westenbroek RE, Yu FH, Cheah CS, Potter GB, Rubenstein JL, Scheuer T, de la Iglesia HO, Catterall WA (2012) Autistic-like behaviour in Scn 1a $+/-$ mice and rescue by enhanced GABA-mediated neurotransmission. Nature 489:385-390.

Hawkins NA, Anderson LL, Gertler TS, Laux L, George AL Jr, Kearney JA (2017) Screening of conventional anticonvulsants in a genetic mouse model of epilepsy. Ann Clin Transl Neurol 4:326-339.

Huang X, Xu W, Liang J, Takagaki K, Gao X, Wu JY (2010) Spiral wave dynamics in neocortex. Neuron 68:978-990.

Jiao J, Yang Y, Shi Y, Chen J, Gao R, Fan Y, Yao H, Liao W, Sun XF, Gao S (2013) Modeling Dravet syndrome using induced pluripotent stem cells (iPSCs) and directly converted neurons. Hum Mol Genet 22:4241-4252.

Khazipov R, Khalilov I, Tyzio R, Morozova E, Ben-Ari Y, Holmes GL (2004) Developmental changes in GABAergic actions and seizure susceptibility in the rat hippocampus. Eur J Neurosci 19:590-600.
Khoshkhoo S, Vogt D, Sohal VS (2017) Dynamic, cell-type-specific roles for GABAergic interneurons in a mouse model of optogenetically inducible seizures. Neuron 93:291-298.

Köhling R, Vreugdenhil M, Bracci E, Jefferys JG (2000) Ictal epileptiform activity is facilitated by hippocampal GABAA receptor-mediated oscillations. J Neurosci 20:6820-6829.

Kramer MA, Cash SS (2012) Epilepsy as a disorder of cortical network organization. Neuroscientist 18:360-372.

Lasztóczi B, Nyitrai G, Héja L, Kardos J (2009) Synchronization of GABAergic inputs to $\mathrm{CA} 3$ pyramidal cells precedes seizure-like event onset in juvenile rat hippocampal slices. J Neurophysiol 102:2538-2553.

Li BM, Liu XR, Yi YH, Deng YH, Su T, Zou X, Liao WP (2011) Autism in Dravet syndrome: prevalence, features, and relationship to the clinical characteristics of epilepsy and mental retardation. Epilepsy Behav 21: 291-295.

Liautard C, Scalmani P, Carriero G, de Curtis M, Franceschetti S, Mantegazza M (2013) Hippocampal hyperexcitability and specific epileptiform activity in a mouse model of Dravet syndrome. Epilepsia 54:1251-1261.

Lima SQ, Hromádka T, Znamenskiy P, Zador AM (2009) PINP: a new method of tagging neuronal populations for identification during in vivo electrophysiological recording. PLoS One 4:e6099.

Liu J, Baraban SC (2019) Network properties revealed during multi-scale calcium imaging of seizure activity in zebrafish. eNeuro 6:ENEURO. 0041-19.2019.

Liu Y, Lopez-Santiago LF, Yuan Y, Jones JM, Zhang H, O'Malley HA, Patino GA, O'Brien JE, Rusconi R, Gupta A, Thompson RC, Natowicz MR, Meisler MH, Isom LL, Parent JM (2013) Dravet syndrome patientderived neurons suggest a novel epilepsy mechanism. Ann Neurol 74: $128-139$.

Meyer J, Maheshwari A, Noebels J, Smirnakis S (2018) Asynchronous suppression of visual cortex during absence seizures in stargazer mice. Nat Commun 9:1938.

Miller AR, Hawkins NA, McCollum CE, Kearney JA (2014) Mapping genetic modifiers of survival in a mouse model of Dravet syndrome. Genes Brain Behav 13:163-172.

Miri ML, Vinck M, Pant R, Cardin JA (2018) Altered hippocampal interneuron activity precedes ictal onset. eLife 7: e40750.

Mistry AM, Thompson CH, Miller AR, Vanoye CG, George AL Jr, Kearney JA (2014) Strain- and age-dependent hippocampal neuron sodium currents correlate with epilepsy severity in Dravet syndrome mice. Neurobiol Dis 65:1-11.

Muldoon SF, Villette V, Tressard T, Malvache A, Reichinnek S, Bartolomei F, Cossart R (2015) GABAergic inhibition shapes interictal dynamics in awake epileptic mice. Brain 138:2875-2890.

Neumann AR, Raedt R, Steenland HW, Sprengers M, Bzymek K, Navratilova Z, Mesina L, Xie J, Lapointe V, Kloosterman F, Vonck K, Boon PAJM, Soltesz I, McNaughton BL, Luczak A (2017) Involvement of fast-spiking cells in ictal sequences during spontaneous seizures in rats with chronic temporal lobe epilepsy. Brain 140:2355-2369.

Oakley JC, Kalume F, Yu FH, Scheuer T, Catterall WA (2009) Temperatureand age-dependent seizures in a mouse model of severe myoclonic epilepsy in infancy. Proc Natl Acad Sci U S A 106:3994-3999.

Ogiwara I, Miyamoto H, Morita N, Atapour N, Mazaki E, Inoue I, Takeuchi T, Itohara S, Yanagawa Y, Obata K, Furuichi T, Hensch TK, Yamakawa K (2007) Nav1.1 localizes to axons of parvalbumin-positive inhibitory interneurons: a circuit basis for epileptic seizures in mice carrying an Scnla gene mutation. J Neurosci 27:5903-5914.

Paz JT, Huguenard JR (2015) Microcircuits and their interactions in epilepsy: is the focus out of focus? Nat Neurosci 18:351-359.

Roche M, Chaigneau E, Rungta RL, Boido D, Weber B, Charpak S (2019) In vivo imaging with a water-immersion objective affects brain temperature, blood flow and oxygenation. eLife 8: e47324.

Rosch RE, Hunter PR, Baldeweg T, Friston KJ, Meyer MP (2018) Calcium imaging and dynamic causal modelling reveal brain-wide changes in effective connectivity and synaptic dynamics during epileptic seizures. PLoS Comput Biol 14:e1006375.

Rossi LF, Wykes RC, Kullmann DM, Carandini M (2017) Focal cortical seizures start as standing waves and propagate respecting homotopic connectivity. Nat Commun 8:217.

Rossi LF, Kullmann DM, Wykes RC (2018) The enlightened brain: novel imaging methods focus on epileptic networks at multiple scales. Front Cell Neurosci 12:82. 
Rudy B, Fishell G, Lee S, Hjerling-Leffler J (2011) Three groups of interneurons account for nearly $100 \%$ of neocortical GABAergic neurons. Dev Neurobiol 71:45-61.

Scheffer IE (2012) Diagnosis and long-term course of Dravet syndrome. Eur J Paediatr Neurol 16:S5-S8.

Sohal VS, Zhang F, Yizhar O, Deisseroth K (2009) Parvalbumin neurons and gamma rhythms enhance cortical circuit performance. Nature 459:698-702.

Steinmetz NA, Buetfering C, Lecoq J, Lee CR, Peters AJ, Jacobs EAK, Coen P, Ollerenshaw DR, Valley MT, de Vries SEJ, Garrett M, Zhuang J, Groblewski PA, Manavi S, Miles J, White C, Lee E, Griffin F, Larkin JDRoll K, Cross S, et al. (2017) Aberrant cortical activity in multiple GCaMP6expressing transgenic mouse lines. eNeuro 4:ENEURO.0207-17.2017.

Sun Y, Paşca SP, Portmann T, Goold C, Worringer KA, Guan W, Chan KC, Gai H, Vogt D, Chen YJ, Mao R, Chan K, Rubenstein JLR, Madison DV, Hallmayer J, Froehlich-Santino WM, Bernstein JA, Dolmetsch RE (2016) A deleterious Nav1.1 mutation selectively impairs telencephalic inhibitory neurons derived from Dravet syndrome patients. eLife 5:e13073.

Tai C, Abe Y, Westenbroek RE, Scheuer T, Catterall WA (2014) Impaired excitability of somatostatin- and parvalbumin-expressing cortical interneurons in a mouse model of Dravet syndrome. Proc Natl Acad Sci U S A 111:E3139-E3148.

Taniguchi H, He M, Wu P, Kim S, Paik R, Sugino K, Kvitsiani D, Kvitsani D, Fu Y, Lu J, Lin Y, Miyoshi G, Shima Y, Fishell G, Nelson SB, Huang ZJ (2011) A resource of Cre driver lines for genetic targeting of GABAergic neurons in cerebral cortex. Neuron 71:995-1013.

Toyoda I, Bower MR, Leyva F, Buckmaster PS (2013) Early activation of ventral hippocampus and subiculum during spontaneous seizures in a rat model of temporal lobe epilepsy. J Neurosci 33:11100-11115.

Toyoda I, Fujita S, Thamattoor AK, Buckmaster PS (2015) Unit activity of hippocampal interneurons before spontaneous seizures in an animal model of temporal lobe epilepsy. J Neurosci 35:6600-6618.
Trevelyan AJ, Schevon CA (2013) How inhibition influences seizure propagation. Neuropharmacology 69:45-54.

Trotter SA, Kapur J, Anzivino MJ, Lee KS (2006) GABAergic synaptic inhibition is reduced before seizure onset in a genetic model of cortical malformation. J Neurosci 26:10756-10767.

Truccolo W, Donoghue JA, Hochberg LR, Eskandar EN, Madsen JR, Anderson WS, Brown EN, Halgren E, Cash SS (2011) Single-neuron dynamics in human focal epilepsy. Nat Neurosci 14:635-641.

Viventi J, Kim DH, Vigeland L, Frechette ES, Blanco JA, Kim YS, Avrin AE, Tiruvadi VR, Hwang SW, Vanleer AC, Wulsin DF, Davis K, Gelber CE, Palmer L, Van der Spiegel J, Wu J, Xiao J, Huang Y, Contreras D, Rogers JA, et al. (2011) Flexible, foldable, actively multiplexed, high-density electrode array for mapping brain activity in vivo. Nat Neurosci 14: $1599-1605$.

Wenzel M, Hamm JP, Peterka DS, Yuste R (2017) Reliable and elastic propagation of cortical seizures in vivo. Cell Rep 19:2681-2693.

Yu FH, Mantegazza M, Westenbroek RE, Robbins CA, Kalume F, Burton KA, Spain WJ, McKnight GS, Scheuer T, Catterall WA (2006) Reduced sodium current in GABAergic interneurons in a mouse model of severe myoclonic epilepsy in infancy. Nat Neurosci 9:1142-1149.

Zhang X, Qiao Z, Liu N, Gao L, Wei L, Liu A, Ma Z, Wang F, Hou S, Li J, Shen H (2019) Stereotypical patterns of epileptiform calcium signal in hippocampal CA1, CA3, dentate gyrus and entorhinal cortex in freely moving mice. Sci Rep 9:4518.

Zhang ZJ, Valiante TA, Carlen PL (2011) Transition to seizure: from "macro"- to "micro"-mysteries. Epilepsy Res 97:290-299.

Zhang ZJ, Koifman J, Shin DS, Ye H, Florez CM, Zhang L, Valiante TA, Carlen PL (2012) Transition to seizure: ictal discharge is preceded by exhausted presynaptic GABA release in the hippocampal CA3 region. J Neurosci 32:2499-2512.

Ziburkus J, Cressman JR, Barreto E, Schiff SJ (2006) Interneuron and pyramidal cell interplay during in vitro seizure-like events. J Neurophysiol 95:3948-3954. 